\title{
Risk of serious infections during rituximab, abatacept and anakinra treatments for rheumatoid arthritis: meta-analyses of randomised placebo-controlled trials
}

\author{
C Salliot, M Dougados, L Gossec
}

René-Descartes University, Medicine Faculty; AP-HP, Cochin Hospital, Rheumatology B Department, Paris, France

Correspondence to:

Dr Carine Salliot, Hôpital Cochin, service de Rhumatologie B, 27 rue du faubourg Saint-Jacques, 75014 Paris, France: carinesalliot@wanadoo.fr

Accepted 6 January 2008 Published Online First 18 January 2008

\begin{abstract}
Background: Tumour necrosis factor $\alpha$ blockers in rheumatoid arthritis are known to increase the risk of serious infections defined as life-threatening, requiring hospitalisation or intravenous antibiotics. Recently, new biological agents have become available. Their safety is an important issue.
\end{abstract}

Purpose: To assess if biological agents, ie rituximab, abatacept and anakinra increase the risk of serious infections in patients with rheumatoid arthritis in published randomised controlled trials.

Data source: A systematic review of the literature using PUBMED, EMBASE, Cochrane library and abstracts databases (American College of Rheumatology and European League Against Rheumatism annual meetings) was performed up to October 2007. This search was completed with data from the Food and Drug Administration, the European Agency for the Evaluation of Medicinal Products and manufacturers.

Data extraction: Three fixed-effect meta-analyses were performed to compare serious infection rates between each biological agent and placebo. Pooled odds ratios (ORs) were calculated, using the Mantel-Haenszel method with a continuity correction.

Data synthesis: Twelve randomised controlled trials with data concerning serious infections were analysed (three for rituximab, five for abatacept and four for anakinra). They included 745 patients, 1960 patients, 2062 patients and 2112 patients treated by rituximab, abatacept, anakinra and placebo respectively. The overall pooled ORs did not reveal a statistically significant increased risk of serious infection for abatacept and rituximab; this risk was increased for high doses of anakinra ( $\geqslant 100 \mathrm{mg}$ daily) versus low dose and placebo (ORs $=9.63(95 \% \mathrm{Cl}, 1.31$ to 70.91$)$ and $3.40(95 \% \mathrm{Cl}$, 1.11 to 10.46$)$ respectively).

Conclusions: These meta-analyses did not reveal a significant increase in the risk of serious infections during rituximab or abatacept treatments in patients with rheumatoid arthritis; however, high doses of anakinra may increase this risk, especially when patients have comorbidity factors. Large studies must be performed to confirm this safety profile in daily practice.

Rheumatoid arthritis (RA) is a systemic autoimmune disorder characterised by chronic polyarticular synovial inflammation that may lead to irreversible joint damage with disability and deformity. This joint inflammation is a result of the excessive production by activated $\mathrm{T}$ cells of pro-inflammatory cytokines, such as tumour necrosis factor (TNF) $\alpha$, interleukin (IL)-1, IL-6, and the stimulation of immunoglobulin production by B cells.

The conventional treatment of RA combines corticosteroids and disease-modifying anti-rheumatic drugs (DMARDs), in particular, methotrexate. However, RA may remain active despite such treatments. Since 1997, new treatments based on biological agents have demonstrated their efficacy in RA. Biotherapies have different therapeutic targets and some are aimed against pro-inflammatory cytokines: three TNF- $\alpha$ blockers are available, infliximab, etanercept and adalimumab ${ }^{1-7}$ and one IL-1 receptor antagonist, anakinra. ${ }^{8}$ Down-regulation of $\mathrm{T}$ cell activation is achieved by the recombinant human fusion protein CTLA-4immunoglobulin G (abatacept) ${ }^{9}$ and $B$ cells are the selective target of the chimeric anti-CD20 monoclonal antibody (rituximab). ${ }^{10}$

Before the biotherapy era, it was reported that the incidence rate of infections in the RA population was nearly twice as high as in matched nonRA controls. ${ }^{11}$ This is thought to be related to the disease itself, which alters immunological functions, decreases mobility and causes skin defects, and also to immunosuppressive drugs, in particular concomitant use of steroids. ${ }^{11}{ }^{12}$ In post-marketing surveillance and observational studies of TNF- $\alpha$ blockers, serious infections (defined as life-threatening or requiring intravenous antibiotics or hospitalisation) appear to be the most frequent adverse event with a prevalence of $6-18 \%$ and an incidence rate of approximately 6 per 100 patientyears. ${ }^{13-15}$ Furthermore, case-control studies, conducted in routine daily practice, showed that the risk of serious infections was two- to three-fold higher in patients receiving TNF- $\alpha$ blockers compared with those not treated with such treatment. ${ }^{13-16}$ Thus it is clear that TNF- $\alpha$ blockers can increase immunosuppression in patients with RA and induce the emergence of serious infections. Meta-analysis is an interesting method to detect such a risk of a relatively rare event: a recent metaanalysis of randomised placebo-controlled trials of monoclonal anti-TNF- $\alpha$ antibodies (infliximab, adalimumab) found a pooled odds ratio (OR) for serious infections of 2.0 (95\% confidence interval (CI), 1.3 to 3.1 ) in TNF- $\alpha$ blocker treated patients. ${ }^{17}$ However, individually, the trials had failed to demonstrate this increased risk of serious infections.

For other biological agents that may interfere with the immune response (rituximab, anakinra, 
abatacept), data on serious infections are lacking. The purpose of this study was to assess if these biotherapies increased the risk of serious infections in patients with RA, by performing a meta-analysis of data published to date.

\section{METHODS}

For each biological agent, a meta-analysis was conducted according to the Cochrane Collaboration guidelines. ${ }^{18}$

\section{Study selection}

A systematic literature search of the literature published up to December 2007 was performed in PUBMED, EMBASE and Cochrane library databases; without limitation of years of publication or journal, using the followings key-words: "rheumatoid arthritis", "abatacept", "rituximab", "anakinra", "clinical controlled trials", "clinical trials", "randomised controlled trials", "clinical trials phase II, III, IV". We also included congress abstracts of American College of Rheumatology (ACR) and European League Against Rheumatism (EULAR) meetings from 2004 to 2006, because we assumed that any abstract published prior to 2004 had been published in a formal fulllength work. Moreover, to complete our search with unpublished data, the Food and Drug Administration (FDA), the European Agency for the Evaluation of Medicinal Products (EMEA) and the manufacturers (Roche, Amgen and BristolMyers Squibb) were contacted.

The trials were initially selected on the basis of their titles and abstract. The inclusion criteria were randomised placebocontrolled trials in adult patients with RA according to ACR criteria. ${ }^{19}$ The publications had to be written in English, French or Spanish. The patients had to be randomised to receive placebo or one of the three biological agents (rituximab, anakinra and abatacept), as monotherapy or with concomitant biological or non-biological DMARDs. Reviews and articles reporting trials that were not placebo-controlled were excluded.

\section{Data collection}

One investigator (CS) selected the articles and collected the data, using a predetermined form. The following methodological features were collected: simple or double blinding, intentionto-treat-analysis or not, number of participants who completed the follow-up. For each trial, demographic characteristics (percentage female, mean age), RA features and its duration, treatment allocation (with doses and duration), concomitant treatments (DMARDs, corticosteroids, non-steroid anti-inflammatory drugs) and duration of follow-up were collected. In the literature, a serious infection is usually defined as life-threatening, requiring intravenous antibiotics or hospitalisations. ${ }^{156}$ This definition was also used here; if another definition of serious infections was given in the trials, it was also recorded. The number of patients with at least one serious infection in placebo and biological agent groups were collected. When available, the characteristics of infections (localisation, organism and outcome) were noted.

\section{Statistical analysis}

For each biological agent, a fixed-effects meta-analysis of dichotomous outcomes was performed. This model has a superior performance to random-effect models when pooling trials with few or no events, such as serious infections. ${ }^{20}$ Because serious infections were rare events and some trials were small, the Mantel-Haenszel method was chosen with a continuity correction when there was no serious infection observed in one study arm of a trial. The Mantel-Haenszel method was used to estimate the pooled OR, with $95 \% \mathrm{CI}$, of all trials, assuming a fixed-effect model. The CIs for ORs were evaluated using the Robins, Breslow and Greenland variance formula and a $\chi^{2}$ test was given with its associated probability that pooled ORs were equal to 1 . These statistical methods applied to each biological agent and for all trials whatever the dose, and for two a priori empirically pre-defined dose groups: low-dose group (500 mg for rituximab, $\leqslant 2 \mathrm{mg} / \mathrm{kg}$ for abatacept and $<100 \mathrm{mg}$ for anakinra) and high-dose group (1000 $\mathrm{mg}$ for rituximab, $10 \mathrm{mg} / \mathrm{kg}$ for abatacept and $\geqslant 100 \mathrm{mg}$ for anakinra). We also performed a sensitivity analysis concerning potential confounding factors of infections. According to Doran et $a l^{21}$ predictive factors of serious infections in patients with RA were increasing age, presence of rheumatoid factor (RF), extra-articular manifestations, nodules, increased erythrocyte sedimentation rate, comorbidities (such as diabetes mellitus, chronic lung disease, alcoholism, organic brain disease, leucopenia) and concomitant steroid treatment. When available, these factors were included in the sensitivity analysis. According to this study, duration of $\mathrm{RA}$, previous and concomitant DMARDs, sex, obesity and smoking status did not appear as predictors of serious infections in patients with RA. We used StatsDirect version 2.5.7 (StatsDirect Ltd, Cheshire, UK) and RevMan version 4.2 (Review Manager, Copenhagen, The Nordic Cochrane Centre, 2003) statistical software.

\section{RESULTS}

\section{Literature search results and trials characteristics}

Figure 1 shows the selection process of published trials for this systematic review. Initially, 490 potentially relevant articles were screened. Among them 477 were excluded. Finally, 13 randomised double-blind placebo-controlled trials were included. $8-1022-31$ The characteristics of these trials are summarised in table 1 . Twelve published trials were selected for the meta-analysis. One article was excluded from the meta-analysis because it reported a trial already selected, with a different follow-up: ${ }^{24} 25$ for the meta-analysis, we selected the longest follow-up (48 vs 24 weeks). No additional randomised controlled trial was available from FDA, EMEA, manufacturers or congress abstracts.

All of these 12 articles were randomised double-blind placebocontrolled trials with a follow-up of 12-48 weeks, for patients with RA according to the ACR criteria and with active disease despite DMARDs. However, three studies concerned patients with RA refractory to TNF- $\alpha$ blocker treatment. ${ }^{9226}$ In all trials, an intention-to-treat analysis was performed and $94 \%$ of the patients included completed the follow-up. Intention-totreat analysis included all randomised patients who received at least one dose of study medication (modified intention-to-treat analysis). Thus a total of 4767 patients received at least one dose of one of the three biological agents and 2112 placebo. Eightyone per cent of the participants were women with a mean age at inclusion of between 46 and 57 years. The mean duration of RA was 9.2 years (range 3.4-12.1).

\section{Serious infections}

According to these trials, serious infection was defined as lifethreatening, fatal, requiring a hospitalisation, intravenous antibiotics, or resulting in persistent or significant disability. Tables 2 and 3 summarise the serious infections reported in the 12 trials, according to treatment groups with incidence and ORs. 


\section{5 potentially relevant publications}

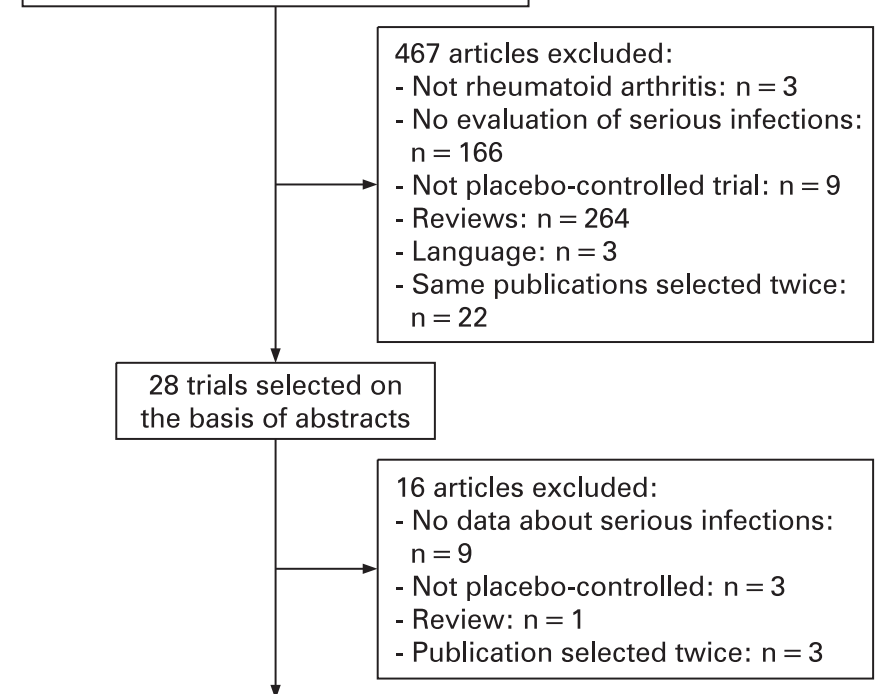

12 trials included in the meta-analysis:

- Rituximab trials: $n=3$

- Abatacept trials: $n=5$

- Anakinra trials: $n=4$

Figure 1 Systematic literature search selection process.

\section{Serious infections during rituximab treatment}

Three trials fulfilled the criteria for analysis ${ }^{1022} 23$ (table 1). Overall, 745 randomised patients with RA received at least one dose of rituximab (500 mg or $1000 \mathrm{mg}$ ) and 398 received at least one dose of placebo. The mean age of patients receiving rituximab was 52.0 years. Among them, 490 had steroids as concomitant treatment (65.7\%) and 331 (among 624 patients tested) were RF positive (82.5\%). For patients allocated to placebo, the mean age was 52.3 years, 253 had steroid treatment (63.5\%) and 207 (among 358 patients tested) were RF positive (83.6\%). Six and 17 serious infections were observed in the placebo and rituximab groups respectively. These 17 serious infections occurred in patients receiving $2 \times 1000 \mathrm{mg}$ infusions of rituximab. No serious infections were observed in those treated with the dose of $500 \mathrm{mg}$ (table 2). The incidence of serious infections was $2.3 \%$ and $1.5 \%$ in the rituximab and placebo groups respectively (table 3 ). Using the Mantel-Haenszel method, the overall pooled OR for serious infections whatever the dose and according to the dose groups were not significantly increased (tables 3 and 4, fig 2). In patients receiving rituximab, serious infections were mainly respiratory tract bacterial infection. Among the 17 patients who had one serious infection: five had bronchopneumonia (one of them presented with two episodes of Pseudomonas aeruginosa pneumonia), two septic arthritis (of whom one Staphylococcus aureus septicaemia), three pyelonephritis and two gastroenteritis and one each epiglottitis, cellulitis of a toe and acute hepatitis B. One fatal bronchopneumonia occurred in a patient receiving rituximab. ${ }^{10}$ No opportunistic infection or tuberculosis occurred in patients receiving rituximab.

\section{Serious infections during abatacept treatment}

Five published placebo-controlled trials fulfilled the selection criteria for analysis $^{95-28}$ (table 1). A total of 2945 randomised patients received at least one dose of abatacept $(0.5,2$ or $10 \mathrm{mg} /$ $\mathrm{kg})(\mathrm{n}=1960)$ or placebo $(\mathrm{n}=985)$ for a duration of treatment comprised between 24 and 48 weeks. One hundred and three participants treated with abatacept and 64 patients receiving placebo had TNF- $\alpha$ blocker or anakinra as concomitant treatment. ${ }^{28}$ In the abatacept groups, the mean age was 49.6 years, 1328 patients received steroids as concomitant treatment $(67.7 \%)$ and $82.5 \%$ (among the 872 patients tested) were RF positive. Concerning placebo groups, the mean age was 48.6 years, 655 patients took concomitant steroid treatment (66.5\%) and $79.8 \%$ (among the 471 patients tested) were RF positive.

In the abatacept group, 49 serious infections were observed versus 18 in the placebo group (tables 2 and 3). Seven serious infections (six in abatacept and one in placebo groups) occurred in patients who received TNF- $\alpha$ blocker or anakinra as concomitant treatment. ${ }^{28}$ Thus, the incidence was $2.5 \%$ and $1.7 \%$ respectively with an overall pooled OR whatever the dose and according to the dose groups not significantly increased (tables 3 and 4, fig 2). The 49 serious infections occurring with abatacept were mainly bronchopulmonary, ${ }^{23}$ streptococcal and pyogenic septicaemia, ${ }^{2}$ staphylococcal arthritis, ${ }^{2}$ abscesses, ${ }^{2}$ gastrointestinal (six of whom three diverticulitis), dermatological infections (six of whom one was a cellulitis) and pyelonephritis. $^{7}$ One case of unconfirmed tuberculosis and one case of pulmonary aspergillosis were reported. The last patient (who had a history of tuberculosis and pulmonary fibrosis) died of aspergillosis and of a Pseudomonas aeruginosa septicaemia.

\section{Serious infections during anakinra treatment}

Four trials were included in the meta-analysis. ${ }^{89-31}$ Their characteristics are summarised in table 1 . The meta-analysis was performed on 2771 patients, randomised to receive at least one dose of anakinra $(\mathrm{n}=2062)(0.04,0.01,0.4,1,2 \mathrm{mg} / \mathrm{kg}, 30$, 75 , 100 or $150 \mathrm{mg}$ ) or placebo ( $\mathrm{n}=729)$, during 24 weeks. Among these participants, 755 and 196 patients (who received anakinra and placebo respectively) had comorbidity factors such as pulmonary chronic disease, diabetes, renal impairment, previous malignancy or infection, cardiovascular or central nervous system diseases. ${ }^{31}$ The proportion of patients with comorbidity factors was similar in the anakinra and placebo groups $(67.6 \%$ and $69.2 \%$ respectively). In the anakinra groups, the mean age was 54.2 years and $53.0 \% \%$ received steroids as concomitant treatment. Concerning placebo groups, the mean age was 55.3 years and $55.0 \%$ received steroids. The prevalence of RF was $74.6 \%$ in the anakinra groups and $75.1 \%$ in placebo groups (for 946 and 446 patients tested respectively). Thirty serious infections $(1.4 \%)$ were observed in the anakinra group versus $4(0.5 \%)$ in placebo group (tables 2 and 3). Nineteen serious infections $(2.5 \%)$ occurred in patients with comorbidity factors and treated with anakinra. ${ }^{31}$ The overall pooled OR of serious infections did not show a significantly increased risk of serious infection. However, the risk was increased for a high dose of anakinra versus low dose and high dose versus placebo (ORs $=9.63$ (95\% CI: 1.31 to 70.91) and 3.40 (95\% CI: 1.11 to 10.46) respectively) (tables 3 and 4 , fig 2 ). When patients with comorbidity factors were excluded, these results were not statistically significant whatever the dose groups (table 4). Among the 30 serious infections occurring in anakinra-treated groups, 11 were pneumonia. The others were osteomyelitis, ${ }^{2}$ cellulitis, ${ }^{3}$ bursitis, herpes zoster, infected bunion and gangrene (one of each). No related death or opportunistic infections were described.

\section{Sensitivity analyses}

Analyses of subgroups according to age $(<$ or $>$ to median, 52.7 years), concomitant intake of steroids (median $65 \%$ of 
Table 1 Characteristics of the 12 randomised controlled trials of biotherapies in RA included in these meta-analyses for serious infections

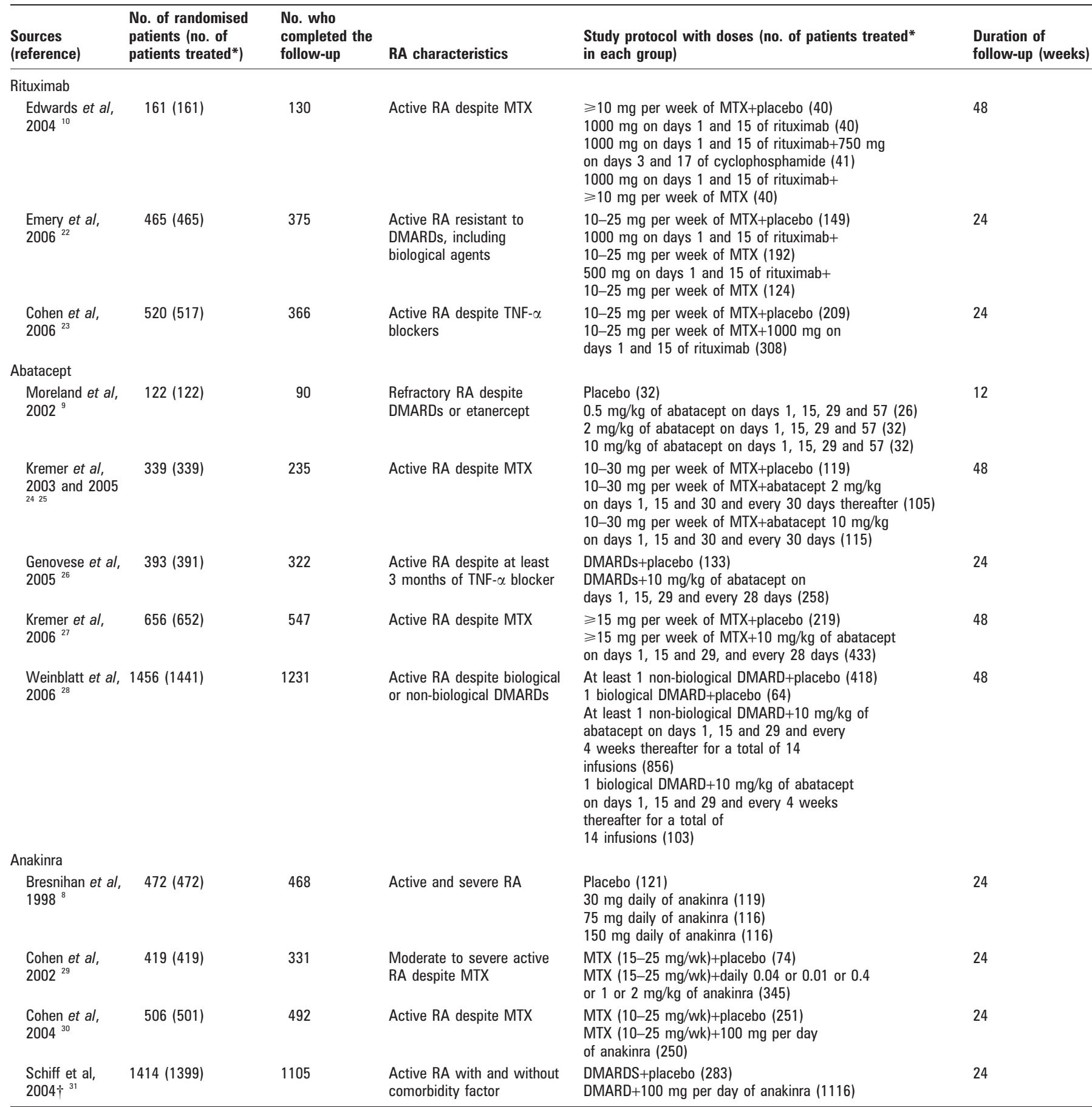

RA, rheumatoid arthritis; MTX, methotrexate; DMARDs, disease-modifying antirheumatic drugs; wk, week.

*Number of patients who received at least one dose of study medication in this arm of randomisation and were analysed.

†'Including 951 patients with comorbidity factors (775 in the anakinra group and 196 in the placebo group).

patients) and RF positivity (median positivity $78 \%$ of patients), confirmed the previous results (data not shown). Thus these potential predictive factors of serious infections did not appear as confounding factors.

\section{DISCUSSION}

These meta-analyses of published data did not evidence an increased risk of serious infections for patients with RA treated by rituximab or abatacept. However, results indicated a significantly increased risk of serious infections for the high dose of anakinra.
The meta-analyses of randomised placebo-controlled trials that evaluated separately these three biotherapies included 12 trials: three for rituximab (745 patients treated), five for abatacept (1960 patients) and four for anakinra (2062 patients). Separately, these trials did not show an increased risk of serious infections except for one concerning patients with comorbidities receiving anakinra. ${ }^{31}$ The calculated pooled ORs, whatever the doses, did not show a significantly increased risk of serious infections in patients treated with these three biological agents. Indeed, overall ORs were 1.45 (95\% CI, 0.56 to 3.73), 1.35 (95\% CI, 0.78 to 2.32 ) and 2.75 (95\% CI, 0.90 to 8.35 ) for rituximab, 
Table 2 Summary of serious infections* in the 12 randomised placebo-controlled trials included in these meta-analyses

\begin{tabular}{|c|c|c|c|c|c|}
\hline Treatment & $\begin{array}{l}\text { No. of trials } \\
\text { (references) }\end{array}$ & $\begin{array}{l}\text { No. of patients } \\
\text { treated } \dagger \text { (biological/ } \\
\text { placebo groups) }\end{array}$ & $\begin{array}{l}\text { Duration of } \\
\text { follow-up } \\
\text { (weeks) }\end{array}$ & $\begin{array}{l}\text { No. of patients with } \\
\text { at least } 1 \text { serious } \\
\text { infection in } \\
\text { biotherapy groups } \\
\text { and by dose group } \\
\text { (no. of participants) }\end{array}$ & $\begin{array}{l}\text { No. of patients } \\
\text { with at least } 1 \\
\text { serious infection } \\
\text { in placebo groups } \\
\text { (no. of participants) }\end{array}$ \\
\hline \multirow[t]{2}{*}{ Rituximab } & $3^{102223}$ & $1143(745 / 398)$ & $24-48$ & $\begin{array}{l}0 \text { Rituximab } \\
500 \mathrm{mg}(124)\end{array}$ & $6(398)$ \\
\hline & & & & 17 Rituximab 1000 mg (621) & \\
\hline \multirow[t]{3}{*}{ Abatacept } & $5^{924-28}$ & $2945(1960 / 985)$ & $24-48$ & 0 Abatacept $0.5 \mathrm{mg} / \mathrm{kg}(26)$ & $18(985)$ \\
\hline & & & & 2 Abatacept 2 mg/kg (137) & \\
\hline & & & & 47 Abatacept 10 mg/kg (1797) & \\
\hline \multirow[t]{9}{*}{ Anakinra } & $4^{829-31}$ & $2771(2062 / 729)$ & 24 & 0 Anakinra $0.04 \mathrm{mg} / \mathrm{kg}(63)$ & $4(729)$ \\
\hline & & & & 0 Anakinra 0.1 mg/kg (74) & \\
\hline & & & & 0 Anakinra $0.4 \mathrm{mg} / \mathrm{kg}$ (77) & \\
\hline & & & & 0 Anakinra 1 mg/kg (59) & \\
\hline & & & & 0 Anakinra 2 mg/kg (72) & \\
\hline & & & & 0 Anakinra $30 \mathrm{mg}$ per day (119) & \\
\hline & & & & 1 Anakinra $75 \mathrm{mg}$ per day (116) & \\
\hline & & & & 25 Anakinra $100 \mathrm{mg}$ per day (1367) & \\
\hline & & & & 4 Anakinra $150 \mathrm{mg}$ per day (116) & \\
\hline
\end{tabular}

*Serious infection was defined as life-threatening, requiring intravenous antibiotics or hospitalisation.

$\uparrow$ Number of patients who received at least one dose of study medication in this arm of randomisation and were analysed.

abatacept and anakinra respectively (table 3). Nevertheless, when high-dose group of anakinra was compared with placebo and low-dose groups, the risk of serious infections was increased during anakinra treatment with ORs of 3.40 (95\% CI, 1.11 to $10.46)$ and 9.63 (95\% CI, 1.31 to 70.91$)$ respectively. For high doses of rituximab and abatacept, we observed a tendency towards an increased risk during biological agent treatments versus low-dose groups: ORs were 7.20 (95\% CI, 0.43 to 120.66) and 2.16 (95\% CI, 0.52 to 8.98$)$ respectively. Thus, although CIs include 1 , there is a lingering concern for infectious risks with these drugs. The serious infections reported were in the majority bacterial and bronchopulmonary. Opportunistic infections seemed to be unusual. Indeed only two were described during abatacept treatment: one case of tuberculosis (unconfirmed) and one of pulmonary aspergillosis.

Randomised controlled trials are often not adapted to demonstrate an increased risk for rare side-effects because the numbers of patients analysed are too small and the exposure time too brief. Post-approval observational studies usually lack a control group, which means establishing causality between a treatment and an event is impossible. Therefore, to pool results of randomised controlled trials by meta-analysis, is an interesting and powerful alternative. ${ }^{17} 19$

Incidences of serious infections observed in the trials analysed are close to other published incidences in RA. Among the 2112 patients receiving placebo, 28 had a serious infection. The

Table 3 Risk of serious infections in patients with RA during rituximab, abatacept and anakinra treatments in randomised placebo-controlled trials

\begin{tabular}{|c|c|c|c|c|}
\hline Source & Treatment & $\begin{array}{l}\text { No. of patients with } \\
\text { at least } 1 \text { serious } \\
\text { infection/total in } \\
\text { treatment groups } \\
\text { (incidence \%) }\end{array}$ & $\begin{array}{l}\text { No. of patients with } \\
\text { at least } 1 \text { serious } \\
\text { infection/total in } \\
\text { placebo groups } \\
\text { (incidence \%) }\end{array}$ & Pooled ORs* (95\% Cl) \\
\hline Edwards et al, 2004 & Rituximab & $6 / 121(4.9)$ & $1 / 40(2.5)$ & $1.45(0.56$ to 3.73$)$ \\
\hline Emery et al, 2006 & & $4 / 316(1.2)$ & $2 / 149(1.3)$ & \\
\hline Cohen et al, 2006 & & 7/308 (2.3) & $3 / 209(1.4)$ & \\
\hline Total & & $17 / 745(2.3)$ & $6 / 398(1.5)$ & \\
\hline Moreland et al, 2002 & Abatacept & 1/90 (1.11) & $0 / 32(0)$ & 1.35 (0.78 to 2.32$)$ \\
\hline Kremer et al, 2005 & & $1 / 220(0.45)$ & $2 / 119(1.7)$ & \\
\hline Genovese et al, 2005 & & $6 / 258(2.3)$ & $3 / 133(2.2)$ & \\
\hline Kremer et al, 2006 & & $13 / 433(3.0)$ & $5 / 219(2.3)$ & \\
\hline Weinblatt et al, 2006 & & $28 / 959(2.9)$ & $8 / 482(1.6)$ & \\
\hline Total & & $49 / 1960(2.5)$ & $18 / 985(1.8)$ & \\
\hline Bresnihan et al, 1998 & Anakinra & $5 / 351(1.42)$ & $1 / 121(0.82)$ & $2.75(0.90$ to 8.35$)$ \\
\hline Cohen et al, 2002 & & $0 / 345(0)$ & $0 / 74(0)$ & \\
\hline Cohen et al, 2004 & & $2 / 250(0.80)$ & $2 / 251(0.8)$ & \\
\hline Schiff et al, 2004 & & $23 / 1116(2.0)$ & $1 / 283(0.3)$ & \\
\hline Total & & $30 / 2062$ (1.4) & $4 / 729(0.5)$ & \\
\hline
\end{tabular}


Rituximab

Odds ratio meta-analysis plot (fixed effects)

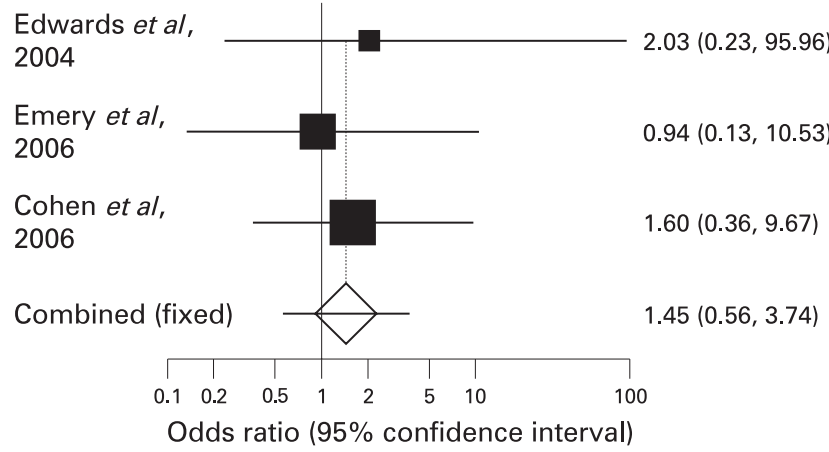

Abatacept

Odds ratio meta-analysis plot (fixed effects)

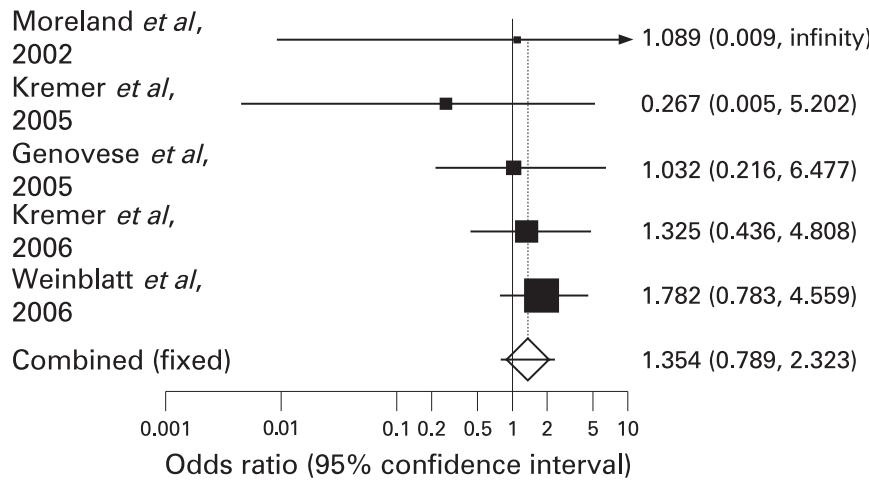

Anakinra

Odds ratio meta-analysis plot (fixed effects)

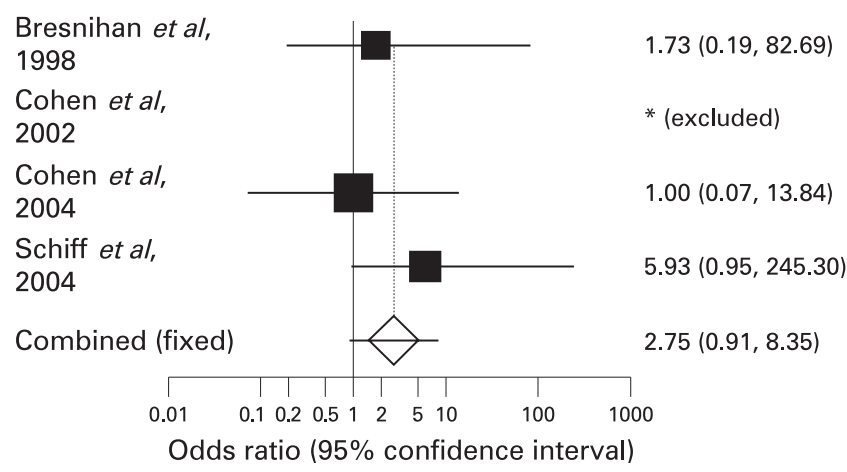

Figure 2 Effect of biological agents (rituxumab, abatacept and anakinra) versus placebo on serious infections (Forest plot).

incidence was $1.3 \%$ and close to the one observed in placebo groups of other controlled trials in patients with RA. Indeed, in the nine randomised controlled trials that evaluated anti-TNF antibodies, 26 serious infections were reported among 1512 patients receiving placebo (incidence 1.7\%). ${ }^{17}$ High-dose anakinra ( $\geqslant 100 \mathrm{mg}$ ) seemed to increase the risk of serious infections. This result concerned 1399 treated patients of whom 755 participants had at least one comorbid condition (such as cardiovascular, pulmonary, diabetes, a history of infection, renal impairment, etc.). ${ }^{31-33}$ Indeed, when we excluded from the metaanalysis the patients with comorbidity, the $\mathrm{OR}$ no longer showed a significantly increased risk in the high-dose anakinra group. Thus comorbidity factors appear to play a part in these
Table 4 Risk of serious infections stratified by high- and low-dose dose groups

\begin{tabular}{|c|c|c|c|}
\hline \multirow[b]{2}{*}{ Treatment } & \multicolumn{3}{|l|}{ ORs (95\% Cls) } \\
\hline & $\begin{array}{l}\text { High-dose* versus } \\
\text { placebo groups }\end{array}$ & $\begin{array}{l}\text { Low-dose } \dagger \text { versus } \\
\text { placebo groups }\end{array}$ & $\begin{array}{l}\text { High-dose* versus } \\
\text { low-dose } † \text { groups }\end{array}$ \\
\hline Rituximab & $\begin{array}{l}1.68 \\
\text { (0.64 to } 4.35)\end{array}$ & $\begin{array}{l}0.24 \\
(0.01 \text { to } 4.33)\end{array}$ & $\begin{array}{l}7.20 \\
(0.43 \text { to } 120.66)\end{array}$ \\
\hline \multirow[t]{2}{*}{ Abatacept } & $\begin{array}{l}1.35 \\
(0.78 \text { to } 2.33)\end{array}$ & $\begin{array}{l}0.84 \\
(0.13 \text { to } 5.30)\end{array}$ & $\begin{array}{l}2.16 \\
(0.52 \text { to } 8.98)\end{array}$ \\
\hline & $\begin{array}{l}1.24 \\
(0.70 \text { to } 2.29) \$\end{array}$ & & $\begin{array}{l}2.0 \\
(0.48 \text { to } 8.33):\end{array}$ \\
\hline \multirow[t]{2}{*}{ Anakinra } & $\begin{array}{l}3.40 \\
(1.11 \text { to } 10.46)\end{array}$ & $\begin{array}{l}0.51 \\
(0.03 \text { to } 8.27)\end{array}$ & $\begin{array}{l}9.63 \\
\text { (1.31 to } 70.91)\end{array}$ \\
\hline & $\begin{array}{l}1.67 \\
(0.51 \text { to } 5.41) \S\end{array}$ & & $\begin{array}{l}6.41 \\
(0.81 \text { to } 50.30) \S\end{array}$ \\
\hline
\end{tabular}

*High-dose groups were defined as $1000 \mathrm{mg}$ for rituximab, $10 \mathrm{mg} / \mathrm{kg}$ for abatacept and $\geqslant 100 \mathrm{mg}$ for anakinra.

†Low-dose groups were defined as $500 \mathrm{mg}$ for rituximab, $\leqslant 2 \mathrm{mg} / \mathrm{kg}$ for abatacept and $<100 \mathrm{mg}$ for anakinra.

†Calculated ORs when patients receiving biological DMARD as concomitant treatment were excluded.

$\S$ Calculated ORs when patients with comorbidity factors were excluded.

results. The long-term safety of anakinra treatment was evaluated in an open-label study following the randomised phase. A total of 1346 patients received anakinra for up to 3 years. ${ }^{34}$ Serious infections were defined as infections necessitating hospitalisation or the use of intravenous antibiotics. The incidence rates (per 100 patient-years) of serious infections concerning patients receiving anakinra were 5.2 during the first placebo-controlled 6 months (versus 1.6 for placebo group) and 5.4 over the 36 months. The most frequent infections were pneumonia and cellulitis. Thus long-term use of anakinra appears to be safe in patients with RA. Nevertheless, this study showed that patients who received steroids as concomitant treatment at baseline were much more likely to experience a serious infection (7.13 per 100 patient-years in patients with steroids versus 2.87 per 100 patient-years for patients without). In this meta-analysis, we could not evaluate the interaction between corticosteroid and anakinra because individual data were not available, the present study cannot fully clarify the issue of an interaction between steroids and anakinra or the role of individual comorbidity factors.

This systematic review was performed using all available literature sources and includes all data published to date. Furthermore, the meta-analysis conforms to the recommendations of the Cochrane collaboration. Therefore we consider these results to be valid. However, this study does have shortcomings. Only published data were analysed, thus we cannot exclude the possibility of publication bias. If the reasons that studies remain unpublished are associated with their outcome, then the results of a meta-analysis could be biased. ${ }^{38}$ Furthermore, biases in patient selection may influence the final results, ie the exclusion from the trials of patients with comorbidities and previous serious infections. However, in four trials evaluating rituximab or abatacept, some patients had received previously one TNF- $\alpha$ blocker. In Genovese's trial, all patients (391) were previously treated with one TNF- $\alpha$ blocker. ${ }^{25}$ These data lacked in Moreland et al's trial. ${ }^{9}$ Concerning rituximab, 769 patients (of the 1143) received previously a TNF blocker. ${ }^{22}{ }^{23}$ It is possible that these patients were not at high risk of serious infection (we suppose that patients previously treated with TNF blockers were screened twice and that those who had a serious infection during the 
TNF blocker treatment were not included in another trial evaluating a biological agent).

These meta-analyses do not demonstrate an increased risk of serious infections with the biological agents analysed. One of the important issues with these results is the potential lack of power. Thus, for each biological agent we calculated a posteriori the number of patients that it would be necessary to analyse in treated and placebo groups to demonstrate the increase in risk that was observed, though it was non-significant, with a power of $80 \%(\alpha$ risk $=5 \%)$. In each group, for rituximab, 4569 patients would be necessary, and 6737 for abatacept. Thus, these meta-analyses are underpowered to detect the observed magnitude of difference in infection risk for these two biological agents. However, for anakinra, the number of patients necessary was 1820 in each group. This meta-analysis included a sufficient number of patients in the anakinra arm (2062) but only 729 patients in the placebo group, thus lack of power is less an issue for anakinra. Because of this lack of power, it is not possible to ascertain completely the absence of infectious risks due to the analysed biological agents.

Like TNF- $\alpha$ blockers, anakinra is an anticytokine biological agent. TNF- $\alpha$ blockers increase the risk of opportunistic infections in patients with RA, most frequently due to intracellular organisms. Tuberculosis, especially extrapulmonary and disseminated, was the most frequently reported granulomatous infection and occurred with the three TNF- $\alpha$ blockers. ${ }^{34.36}$ Invasive opportunistic infections occurring with the three TNF- $\alpha$ blockers have been reported, such as listeriosis, candidosis, histoplasmosis, nocardiosis, aspergillosis, pneumocystosis, etc. ${ }^{39-41}$ In the present meta-analysis, tuberculosis and opportunistic infections seem to be exceptional during rituximab, abatacept or anakinra treatments, thus demonstrating the difference in mechanisms of action between these biotherapies, especially against intracellular organisms.

According to these meta-analyses performed on the basis of randomised placebo-controlled trials, rituximab, abatacept and anakinra seem to be safe as regards the risk of serious infections. Nevertheless, an increased risk was observed for high doses of anakinra ( $\geqslant 100 \mathrm{mg}$ ) in patients with comorbidity factors. Moreover, such clinical trials select patients who are not representative of all patients with RA in daily practice. Thus the use of these biological agents will require careful monitoring in daily practice especially in patients with comorbidity conditions and with concomitant treatments, such as steroids. Further, large-scale, post-marketing studies will have to confirm these data.

Competing interests: CS has received grants for projects with Abbott. MD has received grants for projects with Wyeth, Schering Plough, Abbott, Roche and Bristol Myers Squibb. Investigator in many clinical trials of biological treaments. LG has received grants for projects with Abbott and Bristol Myers Squibb.

\section{REFERENCES}

1. Maini R, St Clair EW, Breedveld F, Furts D, Kalden J, Weisman M, et al. Infliximab (chimeric anti-tumour necrosis factor alpha monoclonal antibody) versus placebo in rheumatoid arthritis patients receiving concomitant methotrexate: a randomised phase III trial. ATTRACT Study Group. Lancet 1999;354:1932-9.

2. Lipsky PE, van der Heijde DM, St Clair EW, Furst DE, Breedveld FC, Kalden JR, et al. Infliximab and methotrexate in the treatment of rheumatoid arthritis. Anti-Tumor Necrosis Factor Trial in Rheumatoid Arthritis with Concomitant Therapy Study Group. N Engl J Med 2000;343:1594-602.

3. Weinblatt ME, Kremer JM, Bankhurst AD, Bulpitt KJ, Fleischmann RM, Fox RI, et al. A trial of etanercept, a recombinant tumor necrosis factor receptor:Fc fusion protein, in patients with rheumatoid arthritis receiving methotrexate. $N$ Engl J Med 1999;340:253-9.

4. Moreland LW, Schiff MH, Baumgartner SW, Tindall EA, Fleischmann RM, Bulpitt KJ, et al. Etanercept therapy in rheumatoid arthritis. A randomized, controlled trial. Ann Intern Med 1999;130:478-86.
5. Moreland LW, Cohen SB, Baumgartner SW, Baumgartner SW, Tindall EA, Bulpitt $\mathrm{KJ}$, et al. Long-term safety and efficacy of etanercept in patients with rheumatoid arthritis. J Rheumatol 2001;28:1238-44.

6. Furst DE, Schiff MH, Fleischmann RM, Strand V, Birbara CA, Compagnone D, et al. Adalimumab, a fully human anti tumor necrosis factor-alpha monoclonal antibody, and concomitant standard antirheumatic therapy for the treatment of rheumatoid arthritis: results of STAR (Safety Trial of Adalimumab in Rheumatoid Arthritis). J Rheumatol 2003;30:2563-71.

7. van de Putte LB, Atkins C, Malaise M, Sany J, Russell AS, van Riel PLCM, et al. Efficacy and safety of adalimumab as monotherapy in patients with rheumatoid arthritis for whom previous disease modifying antirheumatic drug treatment has failed. Ann Rheum Dis 2004;63:508-16.

8. Bresnihan B, Alvaro-Gracia JM, Cobby M, Doherty M, Domljan Z, Emery P, et al. Treatment of rheumatoid arthritis with recombinant human interleukin-1 receptor antagonist. Arthritis Rheum 1998;41:2196-204.

9. Moreland LW, Alten R, Van den Bosch F, Appelboom T, Leon M, Emery P, et al. Costimulatory blockade in patients with rheumatoid arthritis: a pilot, dose-finding, double-blind, placebo-controlled clinical trial evaluating CTLA-4lg and LEA29Y eightyfive days after the first infusion. Arthritis Rheum 2002;46:1470-9.

10. Edwards JC, Szczepanski L, Szechinski J, Filipowicz-Sosnowska A, Emery P, Close $\mathrm{DR}$, et al. Efficacy of B-cell-targeted therapy with rituximab in patients with rheumatoid arthritis. N Engl J Med 2004;350:2572-81.

11. Doran MF, Crowson CS, Pond GR, O'Fallon WM, Gabriel SE. Frequency of infection in patients with rheumatoid arthritis compared with controls: a population-based study. Arthritis Rheum 2002;46:2287-93.

12. Singh G, Ramey DR, Rausch PL, Schettler JD. Serious infections in rheumatoid arthritis: relationship to immunosuppressive use. Arthritis Rheum 1999;42(abstract):S71-474.

13. Kroesen S, Widmer AF, Tyndall A, Hasler P. Serious bacterial infections in patients with rheumatoid arthritis under anti-TNF-alpha therapy. Rheumatology 2003;42:617-21.

14. Listing J, Strangfeld A, Kary S, Rau R, von Hinueber U, Stroyanova-Scholz M, et al Infections in patients with rheumatoid arthritis treated with biologic agents. Arthritis Rheum 2005;52:3403-12.

15. Neven N, Vis M, Voskuyl AE, Wolbink GJ, Nurmohamed MT, Dijkmans BA, et al. Adverse events in patients with rheumatoid arthritis treated with infliximab in daily clinical practice. Ann Rheum Dis 2005;64:645-6.

16. Salliot C, Gossec L, Ruyssen-Wittrand A, Luc M, Duclos M, Guignard S, et al. Infections during tumor necrosis factor $\alpha$ blocker therapy for rheumatic diseases in daily practice: a systematic retrospective study of 709 patients. Rheumatology (Oxford) 2007;46:327-34.

17. Bongartz T, Sutton AJ, Sweeting MJ, Buchan I, Matteson EL, Montori V. Anti-TNF antibody therapy in rheumatoid arthritis and the risk of serious infections and malignancies: systematic review and meta-analysis of rare harmful effects in randomized controlled trials. JAMA 2006;295:2275-85.

18. Cochrane Collaboration guidelines available on http://www.cochrane.org/resources/ handbook4.2.6sep2006.pdf

19. Arnett FC, Edworthy SM, Bloch DA, McShane DJ, Fries JF, Cooper NS, et al. The American Rheumatism Association 1987 revised criteria for the classification of rheumatoid arthritis. Arthritis Rheum 1988;31:315-24.

20. Sweeting MJ, Sutton AJ, Lambert PC. What to add to nothing? Use and avoidance of continuity correction in meta-analysis of sparse data. Stat Med 2004;23:1351-75.

21. Doran MF, Crowson CS, Pond GR, O'Fallon WM, Gabriel SE. Predictors of infection in rheumatoid arthritis. Arthritis Rheum 2002;46:2294-300.

22. Emery P, Fleischmann R, Filipowicz-Sosnowska A, Schechtman J, Szczepanski L, Kavanaugh A, et al. DANCER Study Group. The efficacy and safety of rituximab in patients with active rheumatoid arthritis despite methotrexate treatment: results of a phase IIB randomized, double-blind, placebo-controlled, dose-ranging trial. Arthritis Rheum 2006;54:1390-400.

23. Cohen SB, Emery P, Greenwald MW, Dougados M, Furie RA, Genovese MC, et al. Rituximab for rheumatoid arthritis refractory to anti-tumor necrosis factor therapy. Results of multicenter, randomised, double-blind, placebo-controlled phase III trial evaluating primary efficacy and safety at twenty-four weeks. Arthritis Rheum 2006:54:2793-806.

24. Kremer JM, Westhovens R, Leon M, Di Giorgio E, Alten R, Steinfeld S, et al. Treatment of rheumatoid arthritis by selective inhibition of T-cell activation with fusion protein CTLA4lg. N Engl J Med 2003;349:1907-15.

25. Kremer JM, Dougados M, Emery P, Durez P, Sibilia J, Shergy W, et al. Treatment of rheumatoid arthritis with the selective costimulation modulator abatacept: twelvemonth results of a phase iib, double-blind, randomized, placebo-controlled trial. Arthritis Rheum 2005;52:2263-71.

26. Genovese MC, Becker JC, Schiff M, Luggen M, Sherrer Y, Kremer J, et al. Abatacept for rheumatoid arthritis refractory to tumor necrosis factor alpha inhibition. N Engl J Med 2005;353:1114-23.

27. Kremer JM, Genant HK, Moreland LW, Russell AS, Emery P, Abud-Mendoza C, et al. Effects of abatacept in patients with methotrexate-resistant active rheumatoid arthritis: a randomized trial. Ann Intern Med 2006 Jun 20;144:865-76. Summary for patients in: Ann Intern Med 2006;144:I18.

28. Weinblatt M, Combe B, Covucci A, Aranda R, Becker JC, Keystone E. Safety of the selective costimulation modulator abatacept in rheumatoid arthritis patients receiving background biologic and nonbiologic disease-modifying antirheumatic drugs: a oneyear randomized, placebo-controlled study. Arthritis Rheum 2006;54:2807-16. 
29. Cohen S, Hurd E, Cush J, Schiff M, Weinblatt ME, Moreland LW, et al. Treatment of rheumatoid arthritis with anakinra, a recombinant human interleukin-1 recepto antagonist, in combination with methotrexate: results of a twenty-four-week, multicenter, randomized, double-blind, placebo-controlled trial. Arthritis Rheum 2002; 46:614-24

30. Cohen SB, Moreland LW, Cush JJ, Greenwald MW, Block S, Shergy WJ, et al. A multicentre, double blind, randomised, placebo controlled trial of anakinra (Kineret), a recombinant interleukin 1 receptor antagonist, in patients with rheumatoid arthritis treated with background methotrexate. Ann Rheum Dis 2004;63:1062-8.

31. Schiff MH, DiVittorio G, Tesser J, Fleischmann R, Schechtman J, Hartman S et al. The safety of anakinra in high-risk patients with active rheumatoid arthritis: six-month observations of patients with comorbid conditions. Arthritis Rheum 2004:50:1752-60.

32. Fleischmann RM, Schechtman J, Bennett R, Handel ML, Burmester GR, Tesser J, et al. Anakinra, a recombinant human interleukin-1 receptor antagonist (r-metHulL1ra), in patients with rheumatoid arthritis: A large, international, multicenter, placebocontrolled trial. Arthritis Rheum 2003;48:927-34.

33. Tesser J, Fleischmann R, Dore R, Bennett R, Solinger A, Joh T, et al. Concomitant medication use in a large, international, multicenter, placebo controlled trial of anakinra, a recombinant interleukin 1 receptor antagonist, in patients with rheumatoid arthritis. J Rheumatol 2004:31:649-54.
34. Fleischmann RM, Tesser J, Schiff MH, Schechtman J, Burmester G-R, Bennet R, et al. Safety of extended treatment with anakinra in patients with rheumatoid arthritis. Ann Rheum Dis 2006;64:1006-12.

35. Keane J, Gershon S, Wise RP, Mirabile-Levens E, Kasznica J, Schwieterman WD, et al. Tuberculosis associated with infliximab, a tumor necrosis factor alpha-neutralizing agent. N Engl J Med 2001;345:1098-104.

36. Mohan AK, Cote TR, Block JA, Manadan AM, Siegel JN, Braun MM. Tuberculosis following the use of etanercept, a tumor necrosis factor inhibitor. Clin Infect Dis 2004;39:295-9.

37. Wolfe F, Michaud K, Anderson J, Urbansky K. Tuberculosis infection in patients with rheumatoid arthritis and the effect of infliximab therapy. Arthritis Rheum 2004;50:372-9.

38. Egger M, Smith GD. Bias in location and selection of studies. BMJ 1998;316:61-6.

39. Wallis RS, Broder MS, Wong JY, Hanson ME, Beenhouwer DO. Granulomatous infectious diseases associated with tumor necrosis factor antagonists. Clin Infect Dis 2004:38:1261-5.

40. Slifman NR, Gershon SK, Lee JH, Edwards ET, Braun MM. Listeria monocytogenes infection as a complication of treatment with tumor necrosis factor alpha-neutralizing agents. Arthritis Rheum 2003:48:319-24.

41. Bergstrom L, Yocum DE, Ampel NM, Villanueva I, Lisse J, Gluck 0, et al. Increased risk of coccidioidomycosis in patients treated with tumor necrosis factor alpha antagonists. Arthritis Rheum 2004;50:1959-66. 